\title{
TELEMEDICINE - A PREDICTOR FOR OVERCOMING THE BARRIER IN THE PROCESS OF TREATMENT OF ELDERLY PEOPLE
}

\author{
Albena Andonova ${ }^{1}$, Deyana Todorova $^{2}$
}

\begin{abstract}
:
Telemedicine allows healthcare professionals to assess, diagnose and treat patients remotely using information and telecommunications technologies. Telemedicine is an evolutionary discovery that is increasingly becoming an important part of medical science and practice.

Objectives: To study and analyze the opinion of physician assistants for telemedicine as a predictor for overcoming the barrier in the process of treatment of elderly people living in small and remote settlements.

Methods: We conducted a survey of the opinion of 80 physician assistants on telemedicine as a predictor for overcoming barriers in the treatment of elderly and senile people living in small and remote settlements.

Results: According to the analysis of the data on the benefits of the introduction of telemedicine and because it is a predictor for overcoming the barrier in the treatment of the elderly and elderly, the following was found:

Medical professionals providing medical care to geriatric patients face a number of challenges that require a timely and adequate response, and telemedicine is a predictor of overcoming the barrier in the process of their treatment. In hard-toreach and remote settlements, there is often a lack of general practitioners, enough outpatient clinics and places to perform activities for the treatment of geriatric patients. In these cases, the application of telemedicine would be adequate. This will increase the possibility of access to adequate medical care. Patients will receive precise and clear instructions. This will reduce the need for transportation or time for patients to access hospitals.

Conclusion: The study allows us to draw the following inferences: Telemedicine is an opportunity to improve and enhance the professional activity of physician assistants working with geriatric patients and the implementation of telemedicine will increase the quality of medical care and health care for the elderly population in remote areas and small settlements.
\end{abstract}

UDC Classification: 614.2, DOI: https://doi.org/10.12955/pmp.v2.162

Keywords: telemedicine, geriatric patients, physician assistant, quality medical care, small and remote settlements

\section{Introduction}

Telemedicine involves the usage of electronic communications and software in order to provide medical services to patients through video and audio connections.

The scope of telemedicine is the remote provision of health services through information and communication technologies that allow the exchange of valid information for the diagnosis, treatment and prevention of diseases and injuries. (WHO, 1997).

Telemedicine ensures efficiency and equity of access to health care (Craig et al., 2005). It improves health care for people with chronic diseases by detecting early signs of deterioration, prompt treatment and advice, the real-time assessment of the clinical status, rehabilitation, etc. (Flodgren et al, 2015).

Telemedicine helps to overcome geographical barriers and improves access to health services. This is especially useful for small and remote settlements where there is a predominantly elderly population as well as groups of people who have difficulty accessing health care. In the context of the COVID-19 pandemic, telemedicine has been successfully used in medical practice (Sinsky et al., 2021). At the same time, inequalities in access to telemedicine are established in elderly people due to financial constraints when purchasing devices as well as physical disabilities such as deafness making it difficult for them to use telecommunication devices (Lam et al., 2020).

Among the key problems of health care in Bulgaria is the provision of affordable and quality prehospital care to the elderly population despite the shortage of medical specialists.

Inaccessible and remote locations are mainly populated by elderly people. Very often there is a lack of general practitioners. In order to provide medical care to the population of these areas general practitioners include physician assistants in their team. These medical specialists have professional qualifications for providing emergency and pre-medical care according to the Unified State

\footnotetext{
${ }^{1}$ Trakia University, Faculty of Medicine, Department of Health Care, e-mail:albena.andonova@trakia-uni.bg, ORCID: 0000-0001-7556-321X

${ }^{2}$ Trakia University, Faculty of Medicine, Department of Health Care, e-mail:deyana.todorova@trakia-uni.bg

ORCID:0000-0002-9534-4417
} 
requirements for acquiring a higher education degree of "Bachelor" in the specialty of "Nurse", "midwife" and "Physician Assistant" (The Unified State requirements, 2016).

Their professional competence allows them to be a potential solution to the problem of a shortage in primary care physicians (Drennan et al., 2015).

Physician assistants are effectively integrated into primary medical care in order to improve the quality of patient care (Bowen et al., 2016).

Physician assistants have their place in primary medical care despite certain restrictions in their contribution (Halter et al., 2013). Paramedics who provide medical care to geriatric patients face a number of challenges that require a timely and adequate response, and telemedicine appears to be a predictor of overcoming the barrier in the process of their treatment. In many cases, the application of telemedicine would be adequate. The result will be an increase in the access to qualified medical care.

The model of work between a doctor, nurse and physician assistants is effective for strengthening the capacity of primary medical care for elderly people, characterized by the increasing severity of chronic diseases and for improving the access to care in rural areas (Xue et al., 2017).

Related to the above, the introduction of telemedicine would compensate for some of the problems and would provide necessary and timely medical care to elderly and senile patients.

\section{Objectives}

To study and analyze the opinion of physician assistants for telemedicine as a predictor for overcoming the barrier in the process of treatment of elderly people living in small and remote settlements.

\section{Methods}

A survey was conducted with physician assistants working in areas with populations of less than 1,000 people.

The study was conducted through a direct anonymous survey with 80 physician assistants in the third quarter of 2019.

The results were processed with Microsoft Office Excel 2016.

\section{Results}

According to the analysis of the data the following was established:

According to the respondents, the study found the most common health problems where telemedicine is the most useful: $70 \%$-in patients with myocardial infarction, $34 \%$ - in stroke patients, $32 \%$ - in patients with cardiovascular disease, $30 \%$ - in trauma patients, $12 \%$ - in patients suffering from alcohol and drug abuse, and $4 \%$ - in patients with indicated cardiovascular diseases and arrhythmias.

\begin{tabular}{|l|l|l|}
\hline Figure 1: The benefits of telemedicine in diseases & $70 \%$ \\
\hline $70 \%$ & & $60 \%$ \\
\hline & & $50 \%$ \\
\hline \\
\hline
\end{tabular}


Respondents also indicate that telemedicine will be useful for monitoring the vital indicators of geriatric patients - 80\% - for controlling hypo- and hyperglycemia, $63 \%$ - for monitoring physiological changes in the body, $47 \%$ - for monitoring edema, rash, decubitus, operative field, wounds, etc. Monitoring these statuses with the help of the elderly person and/or his relatives will allow the physician assistants to make independent decisions to continue the patient's treatment as well as whether the patient needs to be consulted by a doctor in the relevant specialty or by general practitioners from emergency medical teams. This will improve the monitoring of the status of elderly people, taking measures to change the therapy or provide timely emergency medical care.

We asked the physician assistants if mobile applications for telemedicine could be used by the elderly people to contact the general practitioner and his medical team. Most respondents - 83\% say "No". In support of this claim, as the main reasons they note, the inability of a large part / 65\% / of elderly people to work with mobile phones and in $36 \%$ of cases - lack of internet or bad internet connection.

The summarized results of the study, related to the introduction of telemedicine in pre-hospital medical care in the Republic of Bulgaria are as follows:

According to $76 \%$ of physician assistants, the introduction of telemedicine in pre-hospital medical care will increase the quality of medical care for the elderly people. A small part of them / 4\% / expressed a negative opinion on this issue, and $16 \%$ cannot judge.

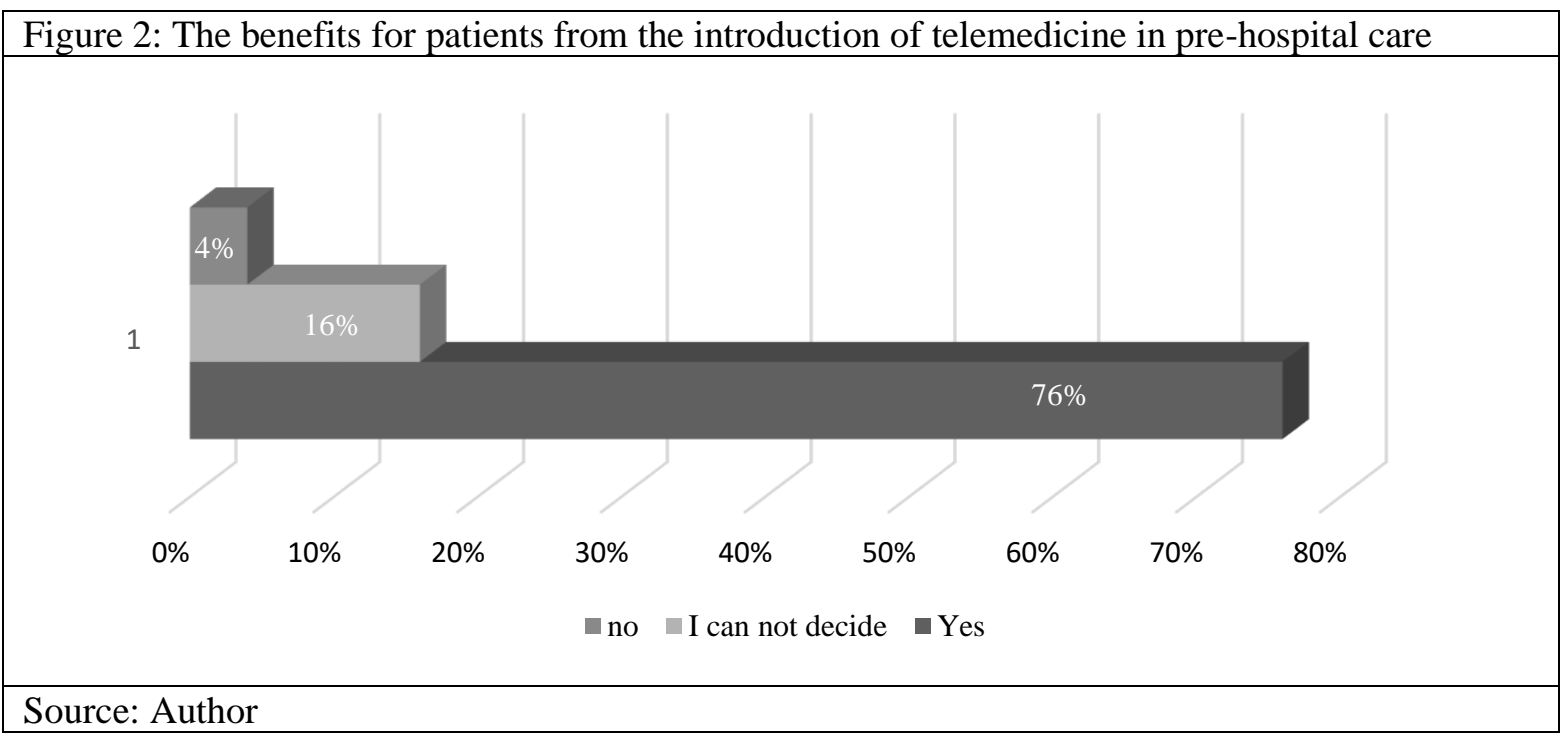

Almost all physician assistants / 95\% / indicate that telemedicine will give them calmness in providing emergency medical care to elderly patients, $56 \%$ - in rehabilitation, $16 \%$ - in monitoring the status of the elderly person.

All surveyed physician assistants working in pre-hospital care believe that they must keep in touch with the general practitioner and the emergency medical teams, $76 \%$ - with a specialist doctor and $23 \%$ - with national consultants.

The respondents say that the problems in outpatient care would be compensated by the introduction of telemedicine, which would improve the communication in medical teams and would provide timely and effective medical care for elderly people living in small settlements.

\section{Conclusion}

The study allows us to draw the following inferences:

1. Telemedicine is an opportunity to improve and enhance the professional activity of physician assistants working with geriatric patients.

2. The implementation of telemedicine will increase the quality of medical care and health care for the elderly population in remote areas and small settlements.

The introduction of telemedicine will contribute to more accurate primary diagnosis and will improve the quality of medical care, provided by physician assistants to geriatric patients. This will provide patients with guaranteed access to quality medical care. 


\section{References}

Bowen, S., Botting, I., Huebner, L. A., Wright, B., Beaupre, B., Permack, S., Jones, I., Mihlachuk, A., Edwards, J., \& Rhule, C. (2016). Potential of physician assistants to support primary care: Evaluating their introduction at 6 primary care and family medicine sites, [Contribution potentielle des assistants médicaux aux soins de première ligne]. Canadian Family Physician, 62(5), e268-e277. Retrieved February 06, 2021, from www.ncbi.nlm.nih.gov/pmc/articles/PMC4865356/

Craig, J., \& Patterson, V. (2005). Introduction to the practice of telemedicine. Journal of telemedicine and telecare, 11(1), 39, doi.org/10.1177/1357633X0501100102

Drennan, V. M., Halter, M., Joly, L., Gage, H., Grant, R. L., Gabe, J., Brearley, S., Carneiro, W., \& de Lusignan, S. (2015) Physician associates and GPs in primary care: a comparison. The British journal of general practice : the journal of the Royal College of General Practitioners, 65(634), e344-e350, doi.org/10.3399/bjgp15X684877

Flodgren, G., Rachas, A., Farmer, A. J., Inzitari, M., \& Shepperd, S. (2015). Interactive telemedicine: effects on professional practice and health care outcomes. The Cochrane database of systematic reviews, 2015(9), CD002098, doi.org/10.1002/14651858.CD002098.pub2

Lam, K., Lu, A. D., Shi, Y., \& Covinsky, K. E. (2020). Assessing Telemedicine Unreadiness Among Older Adults in the United States During the COVID-19 Pandemic. JAMA internal medicine, 180(10), 1389-1391.

doi.org/10.1001/jamainternmed.2020.2671

Halter, M., Drennan, V., Chattopadhyay, K., Carneiro, W., Yiallouros, J., de Lusignan, S., Gage, H., Gabe, J., \& Grant, R. (2013). The contribution of physician assistants in primary care: a systematic review. BMC health services research, 13, 223, doi.org/10.1186/1472-6963-13-223

Katelieva D. (2017). Koga telemeditsinata shte navleze v dobolnichnata speshna pomosht u nas?, [When will telemedicine enter the pre-hospital emergency care in our country?]. Retrieved February 02, 2021

http://cardiobg.com/index.php?option=com_content\&view=article \&id=1898\&catid=48\&Itemid=124

Sinsky, C. A., Jerzak, J. T., \& Hopkins, K. D. (2021). Telemedicine and Team-Based Care: The Perils and the Promise. Mayo Clinic proceedings, 96(2), 429-437. doi.org/10.1016/j.mayocp.2020.11.020

Unified state requirements. Naredba za edinnite darzhavni iziskvaniya za pridobivane na visshe obrazovanie po spetsialnostite "meditsinska sestra", "akusherka" i "lekarski asistent" za obrazovatelno-kvalifikatsionna stepen

"bakalavar".(2016) [The Unified state requirements for acquiring higher education in the specialty "Nurse", "midwife" and "Physician Assistant" educational qualification degree "Bachelor"]. Retrieved March 18, 2021 from https://lex.bg/laws/ldoc/2135513453

WHO. (2017, December 11-16). A health telematics policy in support of WHO's Health-For-All strategy for global health development: report of the WHO group consultation on health telematics. Retrieved February 10, 2021, from https://apps.who.int/iris/bitstream/handle/10665/63857/WHO_DGO_98.1.pdf?sequence=1\&isAllowed=y

Xue, Y., Goodwin, J. S., Adhikari, D., Raji, M. A., \& Kuo, Y. F. (2017). Trends in Primary Care Provision to Medicare Beneficiaries by Physicians, Nurse Practitioners, or Physician Assistants: 2008-2014. Journal of primary care \& community health, 8(4), 256-263. doi.org/10.1177/2150131917736634 